
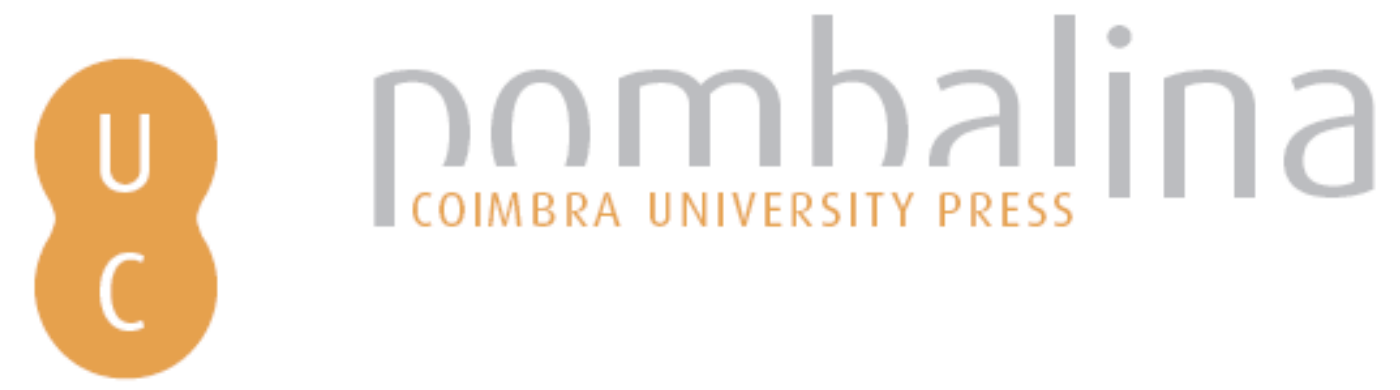

\title{
Abuso sexual de crianças por adolescentes inimputáveis em razão da idade: um desafio ao processo tutelar educativo
}

Autor(es): $\quad$ Sottomayor, Maria Clara

Publicado por: Imprensa da Universidade de Coimbra

URL

persistente: URI:http://hdl.handle.net/10316.2/38892

DOI: $\quad$ DOI:http://dx.doi.org/10.14195/978-989-26-1113-6_14

Accessed : $\quad$ 26-Apr-2023 16:36:24

A navegação consulta e descarregamento dos títulos inseridos nas Bibliotecas Digitais UC Digitalis, UC Pombalina e UC Impactum, pressupõem a aceitação plena e sem reservas dos Termos e Condições de Uso destas Bibliotecas Digitais, disponíveis em https://digitalis.uc.pt/pt-pt/termos.

Conforme exposto nos referidos Termos e Condições de Uso, o descarregamento de títulos de acesso restrito requer uma licença válida de autorização devendo o utilizador aceder ao(s) documento(s) a partir de um endereço de IP da instituição detentora da supramencionada licença.

Ao utilizador é apenas permitido o descarregamento para uso pessoal, pelo que o emprego do(s) título(s) descarregado(s) para outro fim, designadamente comercial, carece de autorização do respetivo autor ou editor da obra.

Na medida em que todas as obras da UC Digitalis se encontram protegidas pelo Código do Direito de Autor e Direitos Conexos e demais legislação aplicável, toda a cópia, parcial ou total, deste documento, nos casos em que é legalmente admitida, deverá conter ou fazer-se acompanhar por este aviso.

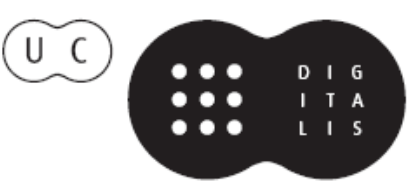




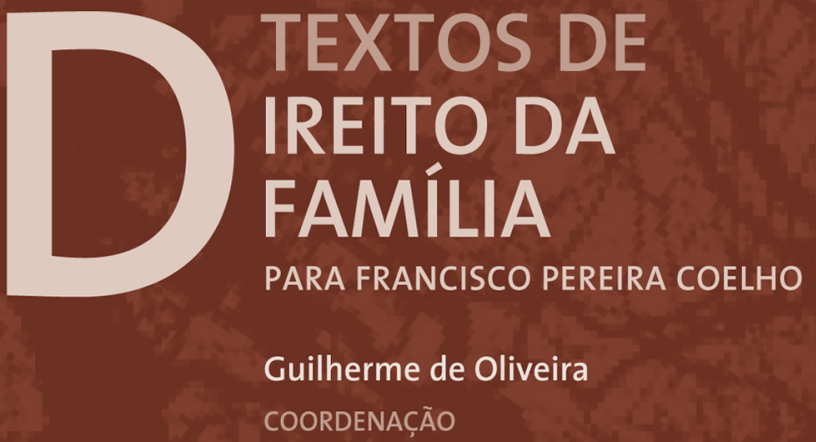




\section{ABUSO SEXUAL DE CRIANÇAS PORADOLESCENTES INIMPUTÁVEIS

\author{
EM RAZÃO DA IDADE：UM DESAFIO
} \\ AO PROCESSO TUTELAR EDUCATIVO ${ }^{1}$}

Maria Clara Sottomayor

Juíza Conselheira do Supremo Tribunal de Justiça Doutorada em Direito Civil pela Universidade Católica Portuguesa Centro de Investigação em Direito da Universidade Católica Portuguesa

\section{Sumário}

Introdução; 1. Abuso sexual de crianças por jovens entre 12 e 16 anos de idade; 2. O testemunho da criança vítima; 3. A audição para memória futura; 4. Medidas tutelares educativas; Conclusão.

\section{Introdução}

A criminalidade sexual caraterizou-se sempre e ainda hoje por uma acentuada invisibilidade e por ser uma área fortemente marcada por preconceitos que prejudicam as vítimas e dificultam a denúncia. Contudo, ser vítima de um crime sexual durante a infância é uma experiência comum a um número muito elevado de pessoas ${ }^{2}$.

\footnotetext{
${ }^{1}$ Aproveito a oportunidade para agradecer à minha amiga Amélia Andrade, docente no ISMAI, a colaboração prestada na revisão do texto e no debate de ideias.

2 Nos EUA, em 1988, 38\% das 930 mulheres inquiridas revelaram ter sido vítimas de pelo menos um crime de abuso sexual antes dos 18 anos
} 
A investigação científica estima que cerca de uma em cada quatro crianças do sexo feminino e uma em cada sete do sexo masculino já foram sexualmente abusadas e que um terço destas crianças é vítima de adolescentes, sendo a esmagadora maioria dos agressores de sexo masculino ${ }^{3}$. Na União Europeia, num inquérito a $42000 \mathrm{mu}-$ lheres, verificou-se que cerca de $12 \%$ foi vítima, antes dos 15 anos de idade, de alguma forma de abuso ou incidente sexual perpetrado por um adulto ${ }^{4}$.

No sistema jurídico português, os menores entre os 12 e os 16 anos não são imputáveis penalmente e os ilícitos criminais que praticam são julgados pelos Tribunais de Família num processo designado por processo tutelar educativo.

Estes jovens são maioritariamente denunciados pela prática de crimes patrimoniais: furtos simples e furtos qualificados ${ }^{5}$.

Mas o sistema intervém também nos casos de jovens denunciados por abuso sexual ou violação de crianças mais novas, ou de outros/ as adolescentes.

A prática judiciária, nos processos tutelares educativos, revela que na realidade social se verificam casos de crianças sexualmente abusadas ou violadas por adolescentes mais velhos, mas que ainda não atingiram a idade de imputabilidade penal.

Cf. DiAnA E. H. RUSSELl, "The Incidence and Prevalence of Intrafamilial and Extrafamilial Sexual Abuse of Female Children", Handbook of Sexual Abuse of Children, LenOre E. A. WALKeR (ed.), New York, 1988, p. 35.

3 Cf. Michael Freeman, "The End Of The Century Of The Child?», Current Legal Problems, 2000, p. 533. Para dados estatísticos referentes a condenações de agressores sexuais menores de idade em Portugal, e para um estudo sobre as variáveis relacionadas com este tipo de criminalidade e sobre as caraterísticas sociais, familiares, psicológicas e de personalidade destes jovens, vide RICARDO BARROSO, Características e especificidades de jovens agressores sexuais, Universidade de Aveiro, Departamento de Educação, 2012, disponível para consulta in http://ria.ua.pt/bitstream/10773/10282/1/Tese.pdf.

${ }^{4}$ Cf. Violência contra as mulheres: um inquérito à escala da União Europeia, Sintese dos resultados, European Union Agency for Fundamental Rights, 2014, p. 13.

5 Cf. BOAVENTURA De SOUSA SANTOS, Entre a Lei e a Prática, Subsídios para uma Reforma da Lei Tutelar Educativa, 2010. 
Se o fenómeno do abuso sexual de crianças ainda não é compreendido e devidamente censurado na sociedade e nos tribunais, o grau de displicência aumenta consideravelmente quando estamos perante ofensas sexuais praticadas por adolescentes contra crianças mais jovens ou crimes sexuais praticados entre adolescentes nas escolas, nas famílias ou nas relações de vizinhança, em que as meninas aparecem como as principais vítimas, estimando-se um predomínio das violações cometidas em grupo por adolescentes do sexo masculino ${ }^{6}$.

Nesta reflexão sobre crimes sexuais cometidos por jovens que não atingiram a idade da imputabilidade penal, vou focar-me nas situações em que a vítima é impúbere ou pré-púbere, deixando de lado os crimes sexuais praticados nas relações entre pares.

É decisivo para compreender o fenómeno que se tenha consciência de que a menoridade não é um estado monolítico e que as crianças passam por diferentes estádios de desenvolvimento, nos quais vão adquirindo progressivamente capacidades.

Os discursos em torno da noção de criança são conflituantes e dependem do contexto.

A noção de infância como fragilidade e necessidade de proteção não se aplica de modo uniforme a todas as crianças qualquer que seja o seu estado de desenvolvimento. Para além do reconhecimento de uma margem de autodeterminação mínima em qualquer idade, a qual se vai alargando progressivamente ao longo do processo de crescimento, nas relações das crianças entre si destaca-se a fragilidade de umas em face da autonomia de outras, pelo facto de se encontrarem em distintas fases de desenvolvimento e/ou pelo facto de se estabelecerem entre elas relações de poder.

\footnotetext{
${ }^{6}$ No estudo de Ricardo Barroso, $60 \%$ das violações cometidas por adolescentes foram praticadas em grupo. RICARDO BARROSO, ob. cit., p. 239.
} 
$\mathrm{O}$ adolescente entre 12 e 16 anos que pratique um ilícito criminal está sujeito a um processo tutelar educativo destinado não a puni-lo mas a educá-lo para o Direito. Desrespeitado o direito à autodeterminação sexual da criança mais nova, estamos perante um ilícito criminal que interessa à ordem jurídica reprimir e perante uma vítima que interessa à ordem jurídica proteger. Contudo, o paradigma de intervenção, em relação a jovens inimputáveis em razão da idade, não é a repressão penal, mas a educação do jovem para que conforme a sua conduta aos ditames da ordem jurídica e ao dever de respeito pelos bens jurídicos fundamentais. Não se aplicam ao processo tutelar educativo as regras do processo penal nem the preside uma lógica sancionatória ou de defesa social. Neste quadro ideológico, poderá entender-se que também os direitos da vítima de crime contra a autodeterminação sexual, reconhecidos pela lei processual penal, devem ceder perante o objetivo de educar o jovem infrator para o Direito? Beneficia ou não a criança vítima dos direitos previstos na lei processual penal e na LPT, como por exemplo, o direito à audição para memória futura (art. 271. ${ }^{\circ}$ do CPP); o direito a distorção da voz e da imagem e a depor por teleconferência (arts. $4 .^{\circ}$ e $5 .^{\circ}$ da LPT7) $o$ direito a não se encontrar com o arguido aquando das diligências probatórias ou do julgamento (art. $29 .^{\circ}$ da LPT e art. $352 .^{\circ}$, n. $^{\circ} 1$, al. b) do CPP); o direito a ser acompanhada por um técnico de serviço social ou por pessoa especialmente habilitada para o efeito e o direito a apoio psicológico (arts. 271..$^{\circ}$ n..$^{\circ} 4$ do CPP e 27. ${ }^{\circ}$ da LPT)?

Deve questionar-se, ainda, qual a medida tutelar educativa a aplicar, de acordo com o princípio segundo o qual as medidas privativas da liberdade constituem uma ultima ratio, mas ponderando-se, também, a eficácia das medidas que mantêm o jovem no seu ambiente natural de vida.

${ }^{7}$ Lei de proteção de testemunhas (Lei n. ${ }^{\circ}$ 93/99, de 14 de julho com as subsequentes alterações). 
Neste artigo trataremos destas três questões: o abuso sexual de crianças cometido por adolescentes entre 12 e 16 anos, o testemunho da vítima e os seus direitos, a audição para memória futura e os critérios de determinação das medidas tutelares educativas aplicáveis ao caso.

\section{Abuso sexual de crianças por jovens entre 12 e 16 anos}

O sistema tende a ver os jovens agressores, na fase da adolescência, como crianças sem maturidade psicológica para compreenderem os seus atos, esquecendo que uma criança impúbere e um adolescente se encontram em fases distintas do seu desenvolvimento e que estas diferenças impedem, de um ponto de vista físico e psicológico, a equiparação de todos os menores. A desvalorização deste fenómeno do abuso de crianças por outras crianças, em estádios de desenvolvimento mais avançados, está relacionada com um conceito pré-concebido e universal de criança que equipara vítimas e agressores. Este conceito afinal não existe e é desmentido pela realidade biológica e psicológica da menoridade, fase da vida humana de natureza marcadamente evolutiva.

Em virtude das diferenças etárias e de desenvolvimento, os menores não são iguais entre si nem têm idêntica capacidade de domínio da sexualidade nem de participação em atos sexuais. Neste contexto, a prática de atos sexuais por jovens adolescentes em crianças não pode ser vista como um jogo sexual ou como uma "brincadeira", mas como um abuso sexual em que o eventual consentimento das crianças impúberes é inválido e irrelevante como seria se o agressor fosse um adulto. A criança mais nova submete-se à atividade sexual, o que é diferente de consentir. $\mathrm{O}$ consentimento requer igualdade de opções, de compreensão e de conhecimento. 
Na hipótese de oposição ou recusa da criança, estamos perante a prática de um crime de violação (art. $164 .^{\circ}$, n. ${ }^{\circ} 1$ do CP) ou de coação sexual (art. 163. ${ }^{\circ}$, n. 1 do CP), embora o Ministério Público, por se tratar de crimes de execução vinculada, que exigem para o preenchimento do tipo a prova da violência ou da ameaça grave, opte, normalmente, por fazer a acusação por abuso sexual de crianças, ficando assim dispensado de um ónus da prova mais gravoso ${ }^{8}$.

A ciência jurídica evoluiu para se adequar aos dados das outras ciências sociais, nomeadamente da psicologia. Aceita-se, hoje, que a menoridade não é um conceito monolítico 9 . O sistema de aquisição da maioridade, no direito português, é um sistema de fixação normativa e automática num limite etário rígido, mas mitigado, que admite espaços de autodeterminação aos adolescentes, de acordo com a sua maturidade, as chamadas maioridades antecipadas, com a atribuição de capacidades aos menores para atos jurídicos específicos ${ }^{10}$. No direito comparado, por exemplo no direito alemão e austríaco, já se adota um sistema gradativo baseado na evolução progressiva da pessoa e acompanhado, no plano jurídico, pelo alargamento da capacidade à medida do desenvolvimento, por fases ou escalões de idade.

As crianças são seres humanos que passam por etapas distintas de desenvolvimento, durante a menoridade, adquirindo capacidades específicas em cada etapa. A própria lei o reconhece, afirmando esferas de autonomia e de maturidade para os menores a partir dos 12

\footnotetext{
${ }^{8} \mathrm{Em}$ face da nova redação dos arts $163 .^{\circ}, \mathrm{n} .^{\circ} 2$ e $164 .^{\circ}, \mathrm{n} .^{\circ} 2$ do $\mathrm{CP}$, introduzida pela Lei n. ${ }^{\circ} 83 / 2015$, de 5 de agosto, os tipos legais de crime de coação sexual e de violação passam a abranger também os casos em que não se verificam os meios de execução vinculada previstos nos arts. $163 .^{\circ}, \mathrm{n} .^{\circ} 1$ e $164 .^{\circ},{ }^{\circ} .^{\circ} 1$, embora com moldura penal mais leve.

9 Rosa MARTINS, Menoridade, (In)capacidade e Cuidado Parental, Centro de Direito da Família da Universidade de Coimbra, Coimbra Editora, 2008, pp. 29-33; CARVAlho Fernandes, Teoria Geral do Direito Civil, Vol. I, Introdução Pressupostos da Relação Jurídica, $5^{\text {a }}$ edição revista e actualizada, Universidade Católica Editora, Lisboa, 2009, pp. 256-257

10 Cf. MARIA Clara SOTTOMAYOR, Temas de Direito das Crianças, Almedina, Coimbra, 2014, p. 14.
} 
anos, reconhecendo-lhes os direitos de intentar uma ação de apadrinhamento civil (art. 10. ${ }^{\circ}$, n. ${ }^{\circ} 1$, al. e) e n. ${ }^{\circ} 2$ da lei n. ${ }^{\circ} 103 / 2009$, de 11 de setembro), de se pronunciarem sobre a sua guarda em casos de divórcio e de solicitarem a nomeação de advogado quando tenham maturidade (arts. 5. ${ }^{\circ}$ e $18 .^{\circ}$ da lei $.^{\circ} 141 / 2015$, de 1 de setembro), de se oporem à intervenção das comissões de proteção de crianças e jovens em perigo (art. 10. ${ }^{\circ}$ da lei n. ${ }^{\circ}$ 147/99, de 1 de setembro) e de consentirem ou não na sua adoção (art. 1981. ${ }^{\circ}$, n. ${ }^{\circ} 1$, a) do CC).

No plano do desenvolvimento sexual, os adolescentes já atingiram a puberdade, adquiriram conhecimentos sobre sexualidade e têm capacidade biológica para uma sexualidade ativa, embora capacidade biológica não coincida com capacidade psíquica e mental, devendo atender-se a esta.

A autodeterminação sexual das crianças é protegida até aos 14 anos, idade até à qual a lei presume iuris et de iure a incapacidade das crianças para prestarem consentimento (art. 171..$^{\circ}$ do CP). A partir dos 14 anos, a lei reconhece, em princípio, aos jovens capacidade para prestarem consentimento válido, mas entre os 14 e os 16 protege os adolescentes contra abusos da sua inexperiência praticados por pessoas maiores de idade (art. $173 .^{\circ}$ do $\mathrm{CP}$ ).

Contudo, pode acontecer que um adolescente, mesmo que com idade inferior a 14 anos, esteja numa situação de poder perante uma criança impúbere e que dela abuse sexualmente. Neste caso, a criança vítima de agressão sexual não tem um desenvolvimento que lhe permita compreender e dominar a sexualidade, nem o seu corpo está sexualizado ou biologicamente preparado para a prática de qualquer ato sexual. Os especialistas afirmam que basta haver entre duas crianças uma diferença de idade de 4-5 anos, para estarmos perante um abuso sexual da criança mais nova ${ }^{11}$.

11 Cf. FINKELHOR, 1984 apud MARISALVA FÁVERO, Sexualidade infantil e abusos sexuais a menores, Climepsi, 2003, p. 72. 
CANTWELL utilizou o conceito de "criança sexualmente agressiva" para designar as crianças que agridem sexualmente outras crianças ${ }^{12}$. A investigação científica, através de estudos em que se verificou que muitos agressores sexuais agrediram pela primeira vez antes dos 16 anos, demonstrou que crianças mais velhas podem agredir sexualmente outras crianças ${ }^{13}$.

Os menores não se encontram em situações de igualdade face ao domínio do corpo e da sexualidade, como se todos tivessem a mesma idade e tivessem capacidade para manter contactos sexuais de livre vontade uns com os outros. É do conhecimento comum que não é assim: os menores, na adolescência, têm capacidade biológica para sexualidade ativa; uma criança impúbere não tem essa capacidade, não só de um ponto de vista psicológico e mental, mas também de um ponto de vista biológico.

\section{O testemunho da criança vítima}

Nos processos tutelares educativos, caraterizados, mesmo após a reforma de 1999 (lei n. ${ }^{\circ}$ 166/99, de 14 de setembro), por alguma informalidade, coloca-se a questão de saber como se faz a prova de um crime sexual e como se recolhe e valora o testemunho da vítima, verificando-se o perigo de as necessidades especiais das crianças vítimas serem apagadas ou obscurecidas pelo estatuto de menoridade do agressor, também fonte de preocupação para o Estado, no domínio da educação e da reinserção social.

12 Cf. CANTwell, 1995, apud MARISAlVA FÁVEro, Sexualidade infantil...ob. cit., p. 72 .

13 Cf. O'DONOHUE E GEER, 1992; MORRISON ET AL., 1994; FORD E LINNEY, 1995, WEINROTT ET AL., 1997 e RENVOIZE, 1993, apud MARISALVA FÁVERO, Sexualidade infantil ... ob. cit., p. 73. 
O testemunho da criança vítima é decisivo para a descoberta da verdade, funcionando como a prova-rainha do processo ${ }^{14}$. Daí que deva ser recolhido com as mesmas cautelas e rigor previstos na lei processual penal e respeitados os direitos da vítima, como exige a legislação de proteção de testemunhas e as diretivas comunitárias.

A circunstância de os exames médico-legais não fornecerem prova positiva não é relevante para efeitos probatórios. A maior parte dos abusos sexuais não deixa marcas físicas e mesmo quando praticados atos de penetração, as crianças recuperam rapidamente das lesões e decorridas $\mathbf{7 2}$ horas sobre os factos normalmente já não se encontram vestígios físicos do abuso sexual, conforme indicam os especialistas ${ }^{15}$.

A investigação científica demonstra que a partir dos 4 anos as crianças têm capacidade de discernimento para distinguirem a fantasia da realidade, a verdade da mentira, e para testemunhar validamente em Tribunal ${ }^{16}$.

Em casos de violência sexual, temática que uma criança não domina, deve presumir-se a veracidade do testemunho, pois não é possível que a criança invente realidades que desconhece. Uma criança não tem conhecimentos de sexualidade para fazer estas narrativas nem para reproduzir narrativas de outrem, a não ser que tenha vivido situações de abuso.

A investigação científica afirma que as regras de produção e de apreciação da prova, nos casos de abuso sexual de crianças, são

${ }^{14}$ Cf. Acórdão da Relação de Guimarães, de 12-04-2010, processo n. ${ }^{0}$ 42/06.2TAMLG. G1, disponível para consulta in http://www.trg.pt/jurisprudencia/acordaostrg.html).

15 Cf. PATRíCIA JARDIM, O abuso sexual na criança, Contributo para a sua caracterização na perspetiva da intervenção médico-legal e forense, Porto, 2011, pp.17-20; TERESA MAGALHÃES/CATARINA RIBEIRO, "A colheita de informação a vítimas de crimes sexuais", Acta Med Port 2007, 20: p. 437, disponível para consulta in http://www.eas.pt/wp-content/uploads/2014/01/A-colheita-de-informa\%C3\%A7_o-ABS_tmagalhaes-e-cribeiro1.pdf

16 Cf. CATARINA RiBeiro, A Criança na Justiça, Trajectórias e Significados do processo Judicial de Crianças Vítimas de Abuso Sexual Intrafamiliar, Coimbra, 2009, pp. 115-117. 
distintas dos outros crimes, sendo importante notar que imprecisões ou contradições nas afirmações da criança não constituem sinais de mentira e que a erosão das lembranças e as dificuldades em estabelecer a sequência cronológica dos factos são normais nas crianças vítimas de abusos sexuais ${ }^{17}$.

\section{Audição da vítima para memória futura}

Tem-se entendido que nos processo tutelares educativos não é necessário haver audição para memória futura da criança vítima de crime contra a autodeterminação sexual, pois com base no art. $106 .^{\circ}$, n. $^{\circ} 2$ da LTE, as declarações reduzidas a escrito da criança vítima podem ser lidas em audiência de julgamento e valem como meio de prova.

Discordo desta interpretação da lei, por entender que priva as crianças vítimas de crimes sexuais, praticados por adolescentes entre os 12 e os 16 anos, dos seus direitos fundamentais e porque a mera leitura das declarações da criança reduzidas a escrito provoca a perda da espontaneidade do testemunho e dos efeitos da imediação da prova.

O Tribunal da Relação de Lisboa, no acórdão de 30-06-2011 (Proc. 4752/10.1T3AMD-A.L1-9), já fixou jurisprudência no sentido da aplicação do art. 271. ${ }^{\circ}$ do CPP aos processos tutelares educativos:

«I. ${ }^{\circ}$ A admissão de declarações para memória futura, no caso previsto no $\mathrm{n}^{\circ} 2$, do art.271, do Código de Processo Penal, visa a protecção do menor vítima de crime contra a liberdade e autodeterminação sexual, poupando-o ao trauma de reviver vezes sem

17 Cf. SOMERS/VANDERMEERSCH, "O registo das audições das crianças vítimas de abusos sexuais", Infância e Juventude, 1998, n. ${ }^{\circ}$ 1, pp. 124-125. 
conta os acontecimentos e ao constrangimento inerente à solenidade e formalismo de uma audiência de julgamento;

II. ${ }^{\circ}$ Aquela norma, por força do art. 128, $\mathrm{n}^{\circ} 1$, da Lei Tutelar Educativa, é subsidiariamente aplicável ao inquérito tutelar educativo, devendo a vítima de menoridade ser ouvida pelo juiz nesta fase processual».

O artigo 271. ${ }^{\circ}$, n. 2 do CPP, sobre a epígrafe "Declarações para memória futura", ao determinar que nos processos por crime contra a liberdade e autodeterminação sexual de menor se procede sempre à inquirição do ofendido no decurso do inquérito, consagra, não apenas um dever de proteção do Estado, mas um direito fundamental da criança cuja efetivação é exigível ao Estado em qualquer processo em que a criança vítima de crime sexual tenha de testemunhar, designadamente nos processos tutelares educativos.

A razão de ser desta disposição legal (art. 271. ${ }^{\circ}$, n. $^{\circ} 2$ do CPP) foi a de evitar a vitimização secundária, ou seja, os danos psíquicos resultantes da participação da criança no processo, nomeadamente os decorrentes da repetição das audições e do encontro com o arguido em audiência de julgamento, os quais podem ser uma fonte de stress tão intensa, ou mais, do que o crime que deu origem ao processo.

A vitimização secundária da criança existe também nos processos tutelares educativos em que a criança tem de testemunhar sobre o abuso cometido por jovens entre os 12 e os 16 anos, justificando-se, assim, a aplicação analógica do art. $271 .^{\circ}$ do CPP à audição da criança vítima de crime sexual no processo tutelar educativo.

A audição para memória futura deve ser gravada com o recurso à vídeoconferência conforme prevê a lei de protecção de testemunhas vulneráveis (arts 4. $.^{\circ}, 5^{\circ}$ e $28 .^{\circ}$ da LPT), para evitar que a criança tenha de depor em audiência de julgamento. O recurso à vídeoconferência permite registar a linguagem não verbal da criança, as suas emoções, silêncios, choros e expressões faciais de medo, conferindo 
ao depoimento fiabilidade, como meio probatório, garantindo a genuidade do seu testemunho e evitando as repetições das entrevistas à criança muitas vezes acompanhadas da recusa desta ou da alteração de factos devido a intervenções de terceiros ou à erosão da memória.

O Protocolo Facultativo à Convenção sobre os Direitos da Criança relativo à venda de crianças, prostituição e pornografia infantis, introduziu no processo penal, destinado a apurar a responsabilidade do autor de crime sexual contra menores, preocupações com as necessidades especiais das crianças e com a defesa do seu interesse. No mesmo sentido, a Diretiva 2011/93/UE do Parlamento Europeu e do Conselho, de 13 de Dezembro de 2011, prevê regras relativas à audição das crianças, no seu art. $200^{\circ}$, onde se estipula que a audição da criança vítima do crime se realize sem demoras injustificadas logo após a denúncia dos factos às autoridades competentes, em instalações concebidas ou adaptadas para o efeito, seja feita por profissionais qualificados para o efeito ou por seu intermédio; o número de inquirições seja o mais reduzido possível; a criança vítima do crime seja acompanhada pelo seu representante legal ou, se for caso disso, por um adulto à sua escolha. Os Estados-Membros devem tomar as medidas necessárias para garantir que, no inquérito, todas as audições da criança vítima do crime ou, se for caso disso, da criança que testemunhou os atos, possam ser gravadas por meios audiovisuais, e que as gravações possam ser utilizadas como prova no processo penal, de acordo com as regras previstas na legislação nacional.

Este procedimento deve ser aplicável, não só aos processos penais, mas também aos processos tutelares educativos. As normas internacionais, que consagram direitos fundamentais das crianças análogos aos direitos, liberdades e garantias previstos na Constituição (art. $17 .^{\circ}$ da CRP), são diretamente aplicáveis a todas as entidades públicas e privadas, nos termos do art. $18 .^{\circ}$, n..$^{\circ} 1$ da CRP, e portanto, também aos tribunais de família, quando instaurado um processo tutelar educativo. 
A audição para memória futura da criança vítima de abuso sexual e a gravação da mesma por vídeoconferência devem ser obrigatórias nos processos tutelares educativos.

O facto de a LTE não prever expressamente estes direitos e diligências não significa o afastamento das normas que se destinam a proteger as crianças vítimas de crimes sexuais.

Deve entender-se que os direitos do jovem infrator devem ceder perante os direitos das crianças vítimas, mais vulneráveis e em perigo de sofrerem os danos psíquicos da vitimização secundária. Por outro lado, estas medidas de proteção não limitam a finalidade do processo tutelar educativo centrada na educação do jovem infrator para o Direito.

Se é certo que nestes processos não preside uma lógica de repressão penal nem de defesa social, também é certo que as crianças vítimas de crimes sexuais praticados por adolescentes não podem ver os seus direitos fundamentais restringidos nem o Estado fica dispensado de lhes fornecer a proteção prevista na lei processual penal.

A consciência de que o agressor menor terá sido muitas vezes vítima de maus tratos ou de abandono e que necessita do apoio da sociedade não nos pode fazer esquecer o sentimento de justiça e as necessidades de proteção das crianças vítimas, que em nada contribuíram para a sociedade criminógena em que vivemos.

\section{Medida tutelar educativa}

Conforme se afirmou no acórdão do Supremo Tribunal de Justiça, de 08-10-2008, processo n. ${ }^{\circ}$ 07P2030, o processo tutelar educativo obedece a uma lógica distinta do processo penal e por isso as regras aplicáveis são também diversas, tal como a filosofia que preside às decisões. No processo penal prevalece a garantia do arguido perante 
o poder punitivo do Estado, mas o objetivo do processo penal é sancionatório, através da prevenção especial e geral. No processo tutelar educativo, como o objetivo é educar para o Direito, não está em causa o poder punitivo mas as necessidades educativas dos menores. Todavia, segundo o artigo $128 .^{\circ},{ }^{\circ}{ }^{\circ} 1$ da LTE, o Código de Processo Penal aplica-se subsidiariamente.

A jurisprudência tem aceite este princípio da aplicação subsidiária das normas processuais penais, no que diz respeito às garantias de defesa e de contraditório. Veja-se, a título de exemplo, o acórdão da Relação de Lisboa, de 10-12-2002 (Proc. 0025865):

«I - Ao Processo Tutelar Educativo previsto na Lei $\mathrm{n}^{\circ}$ 166/99, de 14/09, aplica-se subsidiariamente o regime estabelecido no CPP. II - Consequentemente, instaurada em tal processo, a fase jurisdicional, nos termos do art. $89^{\circ}$ e segs., nela devem respeitar-se o princípio do contraditório e do acusatório".

Contudo, esta regra da aplicação subsidiária do direito processual penal cede perante a consideração das especificidades do processo tutelar educativo e pela resolução do caso não previsto expressamente na LTE à luz da teleologia inerente ao processo, como demonstra o acórdão do Supremo Tribunal de Justiça, de 08-10-2008, que recusou a aplicação da regra do processo penal que manda descontar, no cumprimento da pena de prisão, o período em que o arguido esteve em prisão preventiva.

Afirma o acórdão citado que:

"Não sendo o direito tutelar um direito punitivo penal, em sintonia, de resto, com o pensamento corrente europeu, muito menos com a finalidade retributiva do mal do crime com o mal de uma pena, a intervenção do Estado para a conformação ao direito é ditada por imperiosa necessidade (princípio da necessidade 
- art. $3^{\circ}$ ) de remediar um deficit de conformação ao dever-ser jurídico mínimo e essencial socialmente reinante».

(...)

«Numa linha de plena congruência com os princípios aplicáveis ao direito tutelar de menores cumpre ter presente que a teleologia das penas criminais se situa num plano quantitativa e qualitativa diferenciado do processo tutelar educativo, aquela orientada, em primeira linha, numa feição pragmática ou utilitarista, para a protecção de bens jurídicos de relevância comunitária, em vista da defesa da sociedade, ou, na impressiva formulação de Jakobs, empenhada na estabilização contrafáctica das expectativas comunitárias na vigência da norma jurídica, postas em crise pela prática de um crime, acentuando o seu carácter público, como preocupação primeira, sem erigir o interesse de ressocialização do condenado como meta primordial, mas como meta desejável, frustrada se o condenado se mostrar incorrigível, ou seja incapaz de emenda cívica».

A prevalência das necessidades educativas do menor infrator sobre a finalidade punitiva do processo penal, esta última ausente no processo tutelar educativo, não significa qualquer lógica desculpabilizante, pois a intervenção educativa deve ser tanto mais intensa quanto mais graves forem os factos praticados pelo menor e quanto maior for a sua insensibilidade aos bens jurídicos violados.

Dada a gravidade dos factos ilícitos criminais, quando consistentes em agressões sexuais de crianças ou de outros(as) adolescentes, os adolescentes agressores revelam uma necessidade elevada de educação para o direito, perante a qual o Estado não se pode abster, sob pena de facilitar a continuação de uma atividade criminosa altamente lesiva das crianças vítimas e de toda a sociedade.

Caso não haja uma intervenção precoce e eficaz do Estado na educação destes jovens, a sociedade corre o risco que sigam carreiras 
criminosas na área da violência sexual contra crianças e pessoas vulneráveis. Sabe-se que $50 \%$ dos agressores sexuais cometeram a sua primeira agressão na adolescência ${ }^{18}$.

A medida aplicada, em regra, deve ser o internamento em estabelecimento educativo e não o acompanhamento educativo com obrigação de frequência de programa de educação sexual, pois esta mantém o jovem em ambiente natural de vida e permite-lhe continuar a atividade criminosa.

A relevância do bem jurídico ofendido - o direito à liberdade e autodeterminação sexual, ao livre desenvolvimento da personalidade e à integridade pessoal, direitos consagrados nos artigos $25^{\circ} \mathrm{e}$ $26^{\circ}$ da CRP - e os direitos da vítima à recuperação psicológica e à reinserção social, consagrados no art. 39. da Convenção dos Direitos das Crianças, assim o exigem.

A escolha da medida a aplicar deve ser orientada pelo interesse do menor infrator (art. 6. ${ }^{\circ},{ }^{\circ} 3$ da LTE), ser adequada e suficiente a obter a sua socialização e implicar uma menor intervenção na autonomia de decisão e de condução da sua vida (art. 6. ${ }^{\circ}$, n. ${ }^{\circ} 1$ da LTE), obtendo-se, assim, uma maior adesão do menor e dos seus representantes.

Apesar de o valor do bem jurídico em causa e a proteção da vítima não estarem expressamente previstos na lei como critérios de escolha da medida tutelar educativa, o respeito pela criança vítima e pelos seus direitos insere-se no art. $7^{\circ}, \mathrm{n} .^{\circ} 1 \mathrm{da}$ LTE, que indica como critérios de determinação da duração das medidas a gravidade do facto e a necessidade de educação do menor para o direito.

Para a determinação da gravidade do facto, deve ter-se em conta os danos morais e psíquicos causados à vítima, a espécie e o modo de execução do facto ou o grau de conhecimento ou a intensidade

18 Cf. MARISAlVA FÁVERO, Sexualidade infantil e abusos sexuais a menores, Climepsi, 2003, p. 73. 
da vontade ${ }^{19}$, aqui se devendo ponderar o caráter premeditado e repetido dos crimes sexuais e o grau de violência que os acompanhou.

Para aferir das necessidades educativas dos menores, deve ponderar-se que estas são mais prementes quando os menores cometem crimes sexuais do que quando cometem crimes contra a propriedade, pois, no primeiro caso, o valor do bem jurídico, numa sociedade que erotiza a violência sexual e desvaloriza a sua gravidade, é mais difícil de assimilar do que o valor do bem jurídico propriedade. Por outro lado, o sistema tutelar educativo aplica medidas de internamento dos jovens quando estes praticam crimes de furto qualificado, não se compreendendo que, quando o bem jurídico ofendido é a autodeterminação sexual, a medida aplicada seja mais leve, por tal entrar em contradição com a hierarquia de valores da Constituição e da ordem jurídica, que assentam no primado da dignidade da pessoa humana e dos seus direitos fundamentais.

O crime de abuso sexual de crianças deixa nas vítimas danos psicológicos de grande gravidade, que alteram o seu equilíbrio biopsicológico para sempre, ficando estas com a dor gravada no seu cérebro e revivendo-a ciclicamente ao longo da vida como os veteranos da guerra, as vítimas de tortura ou de campos de concentração ${ }^{20}$.

Os menores agressores têm de se consciencializar da gravidade dos factos praticados e da sua inaceitabilidade pela sociedade e pela ordem jurídica.

O processo tutelar educativo é distinto do processo-crime. Visa educar e não punir. Educar passa por incutir nos jovens infratores as normas pelas quais deve ser regulado o seu comportamento e a aquisição de recursos que lhes permitam, no futuro, conduzir a sua vida de modo social e juridicamente responsável (art. 17. ${ }^{\circ}$, n. $^{\circ} 1$ da

19 Cf. ANABela Miranda Rodrigues/António CARlos DuARTE Fonseca, Comentário da Lei Tutelar Educativa, Coimbra Editora, 2003, p. 72.

20 Cf. JUDith HERMAn, Trauma and Recovery, Basic Books, 1992, pp. 86-95. 
LTE), objetivo que, nos casos de maior indiferença pelos valores da ordem jurídica como o caso da criminalidade violenta, só se garante em regime de internamento. A medida privativa da liberdade cria um ambiente mais propício à reflexão e à interiorização do valor da dignidade da pessoa humana, a base do Estado de Direito. Por outro lado, como demonstra a investigação científica, estando a prática de crimes sexuais muitas vezes associada ao consumo de pornografia ${ }^{21}$, comum entre os jovens agressores sexuais, há que garantir que cessa esta prática, o que só será possível através de uma medida de internamento, em que o jovem seja afastado do seu meio natural de vida.

O acompanhamento educativo para frequência de programa de educação sexual (art. 16..$^{\circ}$ n..$^{\circ} 1$ e n. ${ }^{\circ} 6$ da LTE) não é uma medida adequada e suficiente para realizar as necessidades dos menores infratores de educação para o direito, no caso da criminalidade sexual contra crianças. A medida tem um elevado potencial educativo, pois o seu conteúdo pode ser muito amplo, combinando-se com outras medidas tutelares, e o seu limite máximo de duração pode atingir um período de 2 anos. Contudo, a sua eficácia é questionável. O acompanhamento educativo exige uma regulamentação adequada dos programas formativos e profissionais especializados para fornecer essa formação, sendo estes objetivos prejudicados pelo pouco investimento do Estado nestas questões. O acompanhamento educativo pode, a título excecional, ser aplicado com a imposição de uma obrigação de residência ao menor junto de pessoa idónea ou em instituição de regime aberto, como condição para a respetiva execução (art. 15. ${ }^{\circ}$ n..$^{\circ} 3$ da LTE). Esta possibilidade é, todavia muito rara, na prática, e depende de regulamentação para a sua

21 Cf. DiAnA RUSSELl AND PURCELL, 2011, «Exposure to Pornography as a Causa of Child Sexual Victimization", disponível para consulta in http://www.dianarussell. com/exposure_to_porn_cause_child_sexual_victimization.html. 
concretização. Por outro lado, a manutenção do menor em ambiente natural de vida pode não ser suficiente para o inibir da prática do ilícito, sobretudo, nos casos em que já repetiu o crime e revelou nos factos crueldade e indiferença pelo outro, como sucede na criminalidade sexual.

A medida alternativa ao internamento não garante, nestes casos mais graves, que os menores efetivamente frequentem o programa e que cessem o comportamento ilícito, pois a vigilância do seu cumprimento pelas equipas técnicas de reinserção social tem-se revelado ineficaz. A possibilidade introduzida pela lei n. ${ }^{\circ}$ 4/2015, de 15 de janeiro de a medida não institucional, em processo de revisão, ser substituída por uma de internamento semiaberto, nos casos em que o facto qualificado como crime praticado pelo menor admita a aplicação de medida de internamento em regime semiaberto ou fechado (art. 138. ${ }^{\circ}$ n. ${ }^{\circ} 2$, al. d) da LTE), constitui uma forma de fazer face ao incumprimento das medidas de acompanhamento educativo, sendo, no entanto, ainda assim, insuficiente, pois não permite a aplicação do internamento em regime fechado que entretanto se revele necessário para a educação do menor em face do incumprimento das medidas não institucionais decretadas e da violação grosseira ou persistente dos deveres inerentes ao cumprimento da medida, nos casos em que se verifiquem os pressupostos do art. 17. ${ }^{\circ}$ n..$^{\circ} 4$ da LTE.

$\mathrm{O}$ internamento em centro educativo garante que os menores frequentam, de facto, o programa e permite a avaliação da personalidade dos menores no dia-a-dia, bem como a sua educação quotidiana, promovendo uma intervenção educativa específica e mais intensa do que a frequência de um programa formativo em meio natural de vida. Nos casos de crimes sexuais ou outros crimes violentos contra as pessoas, o internamento tem finalidades pedagógicas e evita também a sensação de impunidade em que vivem os agressores sexuais numa cultura que desvaloriza e até legitima e incentiva a violência sexual. Por outro lado, pertencendo agressor 
e vítima à mesma comunidade, como normalmente sucede, há que proteger a vítima da repetição do crime e do trauma do reencontro com o agressor. A vítima também é criança e mais vulnerável do que o jovem agressor. Deve, por isso, ver os seus direitos ao livre desenvolvimento da personalidade, à integridade psíquica e moral, bem como à recuperação psicológica protegidos com a aplicação da medida. A interiorização dos valores e bens jurídicos violados pelo jovem infrator é um objetivo que se promove de forma mais adequada se a medida aplicável promover também a proteção da vítima.

\section{Conclusão}

Não existe uma noção universal e monolítica de infância. A menoridade divide-se em fases representativas de cada estádio de desenvolvimento das crianças e tem em conta a capacidade natural das crianças para a prática de certos atos de acordo com escalões etários. Em virtude das diferenças etárias, os menores não são iguais entre si nem têm idêntica capacidade de domínio da sexualidade nem de participação em atos sexuais. Neste contexto, a prática de atos sexuais por jovens adolescentes em crianças não pode ser vista como um jogo sexual ou como uma "brincadeira", mas como um abuso sexual em que o eventual consentimento das crianças impúberes ou pré-púberes é inválido e irrelevante como seria se o agressor fosse um adulto.

O sistema de justiça de menores assentou sempre na convicção, fundada nos dados estatísticos, de que a maioria dos menores autores de factos ilícitos criminais são jovens carenciados economicamente que praticam pequenos furtos, e que estas situações são fruto de injustiças sociais, carecendo de medidas assistenciais e não de medidas de internamento em centro educativo. Contudo, o discurso proferido para os crimes patrimoniais não pode ser generalizado 
aos crimes que envolvem violência sexual contra crianças e pessoas vulneráveis. Os estudos sobre delinquência juvenil devem frisar a especificidade dos crimes sexuais de adolescentes contra crianças mais jovens e o seu carácter traumatizante para as vítimas, que não são menos vítimas nem sofrem menos pelo facto de o agressor ser menor de idade, devendo os seus direitos e necessidades de proteção ser salvaguardados no processo tutelar educativo tal como no processo penal. 
(Página deixada propositadamente em branco) 